\title{
Poultice Dosage Form Category
}

National Cancer Institute

\section{Source}

National Cancer Institute. Poultice Dosage Form Category. NCI Thesaurus. Code C154595.

A type of semi-solid pharmaceutical dose form consisting of a moist mass, such as meal, herbs, seeds, etc., usually held within or spread upon an appropriate permeable material or dressing. 